\title{
Effects of Differential Approach on Motivation and Performance of Diverse Learners at Secondary Level in Punjab
}

\author{
* Mrs. Asif-Un-Nisa, PhD Scholar (Corresponding Author) \\ ** Dr. Munnaza Ambreen, Assistant Professor
}

\begin{abstract}
The present study determines the impact of differentiated instructional strategy on motivation and performance of diverse learners at the secondary level in terms of socioeconomic backgrounds, abilities \& learning styles. The study was experimental, and the design of the study was Pre-test, Posttest control group. For this purpose, 70 students of class IX were selected randomly out of 175 students at Government Girls High School who were selected from District Rawalpindi. Two heterogeneous groups having an equal number of students were made. The students in the control group were taught by a conventional approach whereas differential technique was applied in the experimental group. For data collection, two instruments "Learning Style Inventory" by Brett Bixler (1998) and Academic Motivation Scale (AMS) by Valleranad (1992) were adopted by the researcher. Learning Style Inventory was used to know the learning style of the students and AMS was administered to measure the motivational level of the diverse learners. The Alpha reliability coefficient was .82 for learning style Inventory and .88 for AMS. Data were analyzed on SPSS by applying means, standard deviation, t-test, and multiple linear regressions. The study showed that there were statistically non- significant differences between the pre-test and post-test on motivation of the control group. However, there were statistically significant differences between the pre-test and post-test on motivation and academic achievement of the experimental group. It was recommended that the use of differentiated instruction by the teacher be adopted for increasing motivation and improving academic scores of diverse learners at the secondary level.
\end{abstract}

Keywords: Motivation, Performance, Diverse Learners.

Introduction

Each student belongs to the unique background, personality, culture, interest, language, and most importantly attitude towards learning. They come to school with unique academic needs as well. Teachers acknowledge that all such elements play a vital role in the learning of students inside the classroom and molding instructions according to the requirements of learners.

Teachers should know about the students whom they are teaching fully so that they can become effective for society. Diversity is a quality or a state of many forms, types, ideas, etc. There are many groups of students in the classroom who have a lot of learning needs. Student diversity depends on socioeconomic conditions, abilities, and preferences, learning styles, etc. Teachers must fulfill the requirements of all students. Diversity is based on understanding each other, recognizing personal differences by accepting and respecting. This difference may correspond to the religious beliefs or other ideologies, ability, social and economic status, gender, race, ethnicity, and age. Diversity is positively discovering the dissimilarities and uniqueness. It is not simply accommodating individual differences but also acceptance and respect (Akey, M, 2006; Amandeep and Gurpreet, 2005; Amaran, D, 2001; Ames, C, 1992; Amuche, C, 2013). In the classroom, "diversity" refers to the style of learning, background, teaching, and language. Due to the large number of learners, teachers need to work hard to use different teaching methods and continuously monitor the classroom's perception so that all students succeed in placing themselves in the classroom. If teachers want to have an effective study session, they must create a classroom where every student should feel accepted and respected. 
Commonly, no two students enter a classroom with the same set of talents, experiences, and needs. The concept of the differential approach was to take every student in the classroom by paying attention to their difference and maximizing their abilities. Primarily, the teacher gears up all the struggle towards the differences among learners. Differentiation is an approach of assuming that each class has many diverse learners and all students can achieve if different methods and activities are used. To fulfill the requirements of learners, the teacher must distinguish between the content for the students (the syllabus), the process (way of teaching), and the product (as the learner demonstrates learning).

Differentiated Learning is a process where teachers improve the learning ability of the students with a combination of their differences, teaching, and evaluation. (Hall, Strangman, and Meyer, 2003). The student population in our school classrooms continues to become more and more diverse, thus bringing many challenges for the teachers. Today's classrooms are so formed that learners differ from socio-economic backgrounds to abilities and styles of their learning. Teacher must fulfill the requirements of students. Secondary Education is the steppingstone towards further study. Teachers play a decisive role in academic achievement because teachers are responsible for turning educational policies into action. Teachers must develop a relationship and get to know their students as unique individuals (Anderson, K. 2007; Armstrong, T, 1998; Armstrong, T, 2003; Arti, M, 1990).

Differentiated Instruction and Motivation are closely related to each other. Motivation is defined as a disposition to something (Bookhart, Walsh, Zientarski, 2006; Ashton, P. 1983) this is the desire to achieve something or achieve something in some way for some reason. Using differentiated training combined with a variety of teaching and learning methods, students are motivated by the different learning styles and reflections in classroom democracy. Distinguished learning is a motivational learning tool. The main task for the teacher is to find out such kinds of students who need a mentor which provides motivation, both extrinsic and intrinsic which helps to excel in subject matter. For a student motivated extrinsically praising and rewarding is the best motivational technique.

Limits are placed on students' achievement in the classroom where one lesson is designed for all learners. Entangled students are still frustrated and confused in the classroom where the differences (Beck, A.T., \& Steer, 1987; Bar, R. 2000). To fulfill the needs of all the learners, there are various methods to differentiate between lessons. The most common differences are the readiness, interest, and learning of each student. If on a pre-assessment basis, the unit will be designed to test different learners in the high, low, and medium achievement areas, then level of preparation of students is very smooth, as they may have different levels of preparation for different content areas and topics.

\section{Literature Review}

Today's classrooms consist of students from a much more varied background than ever. This phenomenon is present from time immemorial. Multiple elements contribute towards effective teaching such as classroom management, use of teaching material, grip on the subject matter, better planning and human relations tend to remain the same. So now there arises a greater need for effective teaching strategies to be employed for better academic achievements than at any other time. Now for better learning teaching activity teachers should adopt new methods of instruction to facilitate learners to achieve educational objectives. Earlier studies (Abbott, Oscar Eban, 2006; Achilles, 1984; Acosta, E, 2001 and Agathe-Gagne, 1993) have pointed out that motivation and inspiration of students by the teachers was necessary that come from diverse background and different social circumstances for the provision of conducive creative environment.

Differentiated Instruction implies that every student should be imparted instruction according to where he or she is, which in turn will maximize an individual's growth and success and helps in the individual's learning (Trace, Hall, Strangman, 2011). Different students should be given different treatment by the educators and every student's nature should be considered while imparting instruction. Giving instruction that is based on an individual's nature will be fruitful than giving the same instruction to all the students (Anderson, 2009). Tomlinson (2000) has further carried the point of Anderson by stating that, the response of the teachers to the difference of students is Differentiation. Moreover, Tomlinson has also said that Differentiated Instruction can be applied to any grade and any level whether high or senior high schools and it depends upon the teachers if they 
want the optimization of an individual's growth and achievement or success, then they have to accommodate their differences.

Students learn in different ways and at a different pace because all of them are not similar or identical in any way. Based on this, Differentiated Instruction provides many options and choices to the students for information and gaining knowledge in many ways in the classroom. The adjustment of lesson content and putting the information before the students need adaptability on the part of the teacher (Tomlinson, 2003).

The present study will replicate the results of Goddard and Goddard (2007) who demonstrated that differentiated instruction when fully implemented, can significantly improve students' achievement. The present study sought to extend the studies of MCAdmin (2001) who reported significant improvement in the test scores of low scoring students in the Rockwood School District (Missouri) following the use of Differentiated Instruction. Koh performed a study on the effectiveness of different levels of self - efficacy for motivating students. Different groups of students were taught by using different strategies, when the students came up with their assigned task for the first time, the positive reinforcement which they received for their first assignment paved the way for the further task. When they got appreciation and praise for their first work, they streamlined their upcoming task. It boosted up their confidence and enhanced their motivation providing the students necessary and proper feedback besides the success factor for the gradual improvement of the students, which was considered very essential for their motivation (Koh, 2006).

So, the first positive response received by the students from their teachers for their first assignment is the major factor for the motivation of students. (Koh, 2000) for future work as well as for the enhancement of their confidence to take risks. The results of the study of Koh revealed that vocabulary items used in technical or vocational education of students were just like the vocabulary and terminology used in the science subject, using of metaphors and scaffoldings for students according to their various levels of self-efficacy proved very useful for them to comprehend and understand the contents at different levels.

In another study Brookhart, Walsh, and Zientarski (2006) determined the relationship of motivational factors with students' assessments. The major components of motivation on which they study based were interest, importance, and value. It was also determined which one of these three proved to be the most significant for student's academic achievements. For this purpose, a student's survey was done by them. It was based on two subjects' social studies and science. The results indicated that students were greatly affected by the environment of the class provided to the students by the teacher. The motivation of students was more when easy assessments were given to them as compared to when difficult assignments were given to them for a solution. Comprehension and understanding of the significance and importance of assessment and interest of students were the key motivational factors for students Brookhartetal. (2006).

According to Mills, (2007) students frustration results in decreased intrinsic motivation so forming groups of mixed ability and cooperative learning will give a sense of pride and elevation which in turn will improve the degree of performance and achievement of the students. The students having lower ability will learn from modeling which will be provided by those students having high ability and a higher degree of confidence. This will ignite Intrinsic motivation in them (Atwell, 1998). Discussion in the classroom increases the learning of students, contents of the subject are clarified, and the student can retain subject material in his memory for a longer period. New ideas are accommodated and put forward (Mckeache, 2006). The natural learning process which is based on the response to student's interests and needs should be promoted and the school should provide such an environment that will prove helpful in independent learning of the students by responding to their emergent needs (Brewster \& Fager, 2002).

Keeping in mind the difference among the students, the teachers should create such an environment in the class where individual differences are addressed by the teacher and every student should be valued. This feeling of 'being valued' becomes very supportive for the student and ultimately enhances his intrinsic motivation which leads to academic attainment. When choices are given to the students they realize that they are answerable for their chosen task which assists them in their growth and maturity. When the instructions are differentiated by the teachers at the tertiary level of education, the students' response seemed quite encouraging. This was indicated by a research done by Ernst and Ernst (2005). Based on the available research in Differentiated Instruction, it is 
anticipated that $9^{\text {th }}$ class students' motivation and academic achievement will be increased by applying differentiated instruction in secondary classrooms. It was assumed that Differentiated Instruction has a positive and significant effect on student's motivation and academic achievement. A conceptual model was developed and through experimentation by applying Differentiated Instruction as intervention, the relationship of independent variable (DI) with dependent variables (motivation and academic achievement) was observed.

\section{Objectives of the Study}

These are given below:

1. To know diversity among secondary school students in terms of socioeconomic background, abilities, and learning styles.

2. To identify the effects of differential approach on performance of diverse learners at Hypothesis Secondary School level.

1. $\quad \mathrm{H}_{0}{ }^{1}$. There is an insignificant difference between the motivational levels of the diverse learners taught English using conventional methods and those taught by the Differentiated Approach.

2. $\mathrm{H}_{0}{ }^{2}$. There is no insignificant difference between the mean performance scores of the diverse learners taught English using conventional methods and those taught by the Differentiated Approach.

\section{Delimitations of the Study}

Delimitations were:

- It was delimited to secondary class (IX) from Government Girls High Schools of the District Rawalpindi. Diversity parameters were delimited to socioeconomic background, ability, and learning style.

\section{Methodology of the Study}

This was experimental research with Pretest, Posttest control group design. All the students and teachers at Government Girls High schools of the District Rawalpindi were the population of study. Sample of one school was chosen randomly from the Government Girls High Schools Rawalpindi, for experimental study. From the available $9^{\text {th }}$ class (full strength=70), all 70 learners were selected for study. A heterogeneous group of students was taken for study. Diverse learners were distributed into two groups having an equal number of students, which were named as experimental and control groups. It was ensured that in the experimental as well as control group there were diverse learners in terms of socio-economic background, ability, and learning style.

\section{Instruments for the Study}

The following instruments were used:

1. Learning style inventory developed by Brett Bixler (1998) was adapted to know the learning style of diverse learners. It was a 24-items survey (statements) having three response categories: Seldom sometimes, often. Statements were based on three primary learning styles: Visual, auditory, and tactile/kinesthetic modality.

2. Academic Motivation Scale (AMS) by Vallerand (1992) was administered in Pre and Posttest to measure the motivation of diverse learners. The instruments had 7-subscales of 28 questions, each consisting of 4 - items question. These questions were assessed on a 7-pointLikert type-scale.

\section{Administration of Tool}

To measure diversity among students, to check their learning style, participants were directly approached from their classrooms and were informed about the objectives of the research. The learners can clear any ambiguity related to the statements. Inventory for learning style was collected back from the students the same day. AMS was administered to measure the motivational level of diverse learners in both groups.

\section{Data Analysis}

Analysis of data was done in SPSS version 21.0 in the form of Mean, Standard Deviation, Pearson Correlation, independent and paired sample t-test, and multiple linear regressions. A T-test was carried out for independent samples for measuring the differences in motivation and academic achievement of control vs. experimental group. A paired sample t-test was performed in sequence to measure the differences in motivation and achievement for post and pretest of control and 
experimental group. For data analysis statistical package for social sciences (SPSS) version 21 was used. After the selection of Diverse Learners, they were distributed into two groups: Control group $(\mathrm{N}=35)$ and Experimental group $(\mathrm{N}=35)$ for experimental study.

Table1: Description of control \& Experimental Group

\begin{tabular}{lccccc}
\hline $\begin{array}{l}\text { Diversity } \\
\text { Parameters }\end{array}$ & \multicolumn{3}{c}{ Control group (N=35) } & \multicolumn{3}{c}{ Experimental group (N=35) } \\
\hline \multirow{4}{*}{ Ability } & Grade/category & Frequency & Percentage & Frequency & Percentage \\
& A $^{+}$ & 2 & $6 \%$ & 2 & $6 \%$ \\
& $\mathrm{~A}$ & 1 & $3 \%$ & 1 & $3 \%$ \\
& $\mathrm{~B}$ & 12 & $34 \%$ & 10 & $28 \%$ \\
\multirow{3}{*}{ socioeconomic status } & $\mathrm{C}$ & 18 & $51 \%$ & 20 & $57 \%$ \\
& $\mathrm{D}$ & 2 & $6 \%$ & 2 & $6 \%$ \\
Learning Style & Low & 9 & $26 \%$ & 11 & $31 \%$ \\
& Middle & 22 & $63 \%$ & 21 & $60 \%$ \\
& High & 4 & $11 \%$ & 3 & $9 \%$ \\
& Auditory & 11 & $31 \%$ & 13 & $38 \%$ \\
& Visual & 14 & $40 \%$ & 11 & $31 \%$ \\
& Kinesthetic & 10 & $29 \%$ & 11 & $31 \%$ \\
\hline
\end{tabular}

The table indicates that in both control \& Experimental Groups $6 \%$ of students have $\mathrm{A}^{+}$ grade, $3 \% \mathrm{~A}, 85 \% \mathrm{~B} \& \mathrm{C}$, and $6 \%$ have grade $\mathrm{D}$ so the baseline of distribution of subjects into control \& Experimental Groups is almost the same. The table also shows diversity parameters SES \& LS of subjects.

Results

Table 2: Mean and Standard Deviation for Control group in pre \& post EAT on basis of Ability $(N=35)$

\begin{tabular}{|c|c|c|c|c|c|}
\hline \multicolumn{6}{|c|}{ Control Group } \\
\hline \multirow{2}{*}{$\begin{array}{l}\text { Variable } \\
\text { Ability }\end{array}$} & & \multicolumn{2}{|c|}{ Pre-test } & \multicolumn{2}{|c|}{ Post-test } \\
\hline & & M & SD & $\mathrm{M}$ & SD \\
\hline $\mathrm{A}^{+}$ & & 55 & 8.48 & 55 & 7.07 \\
\hline A & 54 & - & 55 & - & \\
\hline B & 42.837 .32 & 42.91 & 7.20 & & \\
\hline $\mathrm{C}$ & & 39.5 & 7.76 & 39.9 & 7.16 \\
\hline $\mathrm{D}$ & & 30.50 & 4.94 & 30.50 & 6.36 \\
\hline
\end{tabular}

As shown in the table there is a statistically insignificant difference in the mean score of the control group in pre $\&$ post-test. Academically high achievers and low achievers reveal no difference in mean score in the pre-\&post-test.

Table 3: Mean and Standard Deviation for Experimental group in pre \& post EAT on basis of Ability $(N=35)$

\begin{tabular}{lccccc}
\hline & \multicolumn{4}{c}{ Experimental Group } \\
\hline Variable & \multicolumn{4}{c}{ Pre-test } & \multicolumn{3}{c}{ Post-test } \\
Ability & $\mathrm{M}$ & $\mathrm{SD}$ & $\mathrm{M}$ & $\mathrm{SD}$ \\
$\mathrm{A}^{+}$ & 57 & 4.24 & 66 & 1.41 & \\
$\mathrm{~A}$ & & 44 & - & 60 & - \\
$\mathrm{B}$ & 43.8 & 6.25 & 54.5 & 6.34 \\
$\mathrm{C}$ & 40.6 & 7.39 & 49.4 & 7.84 \\
D & 35 & 8.48 & 50 & 4.14 \\
\hline
\end{tabular}

As shown in the table there is a statistically significant difference in the mean score of the experimental group in pre \& post-test. Academically high achievers and low achievers reveal differences in mean score in pre \& post-test as the mean score in the post-test is higher than the pretest.

Table 4:Descriptive Statistics and paired sample t-test for motivation on Experimental group $(N=35)$

\begin{tabular}{|c|c|c|c|c|c|c|c|c|c|}
\hline \multirow[b]{2}{*}{ Outcome } & \multicolumn{2}{|c|}{ Pre-test } & \multicolumn{2}{|c|}{ Post-test } & \multicolumn{2}{|r|}{ 95\% CI for Mean } & \multirow[b]{2}{*}{$\mathrm{r}$} & \multirow[b]{2}{*}{$\mathrm{t}$} & \multirow[b]{2}{*}{$\mathrm{P}$} \\
\hline & $\mathrm{M}$ & SD & $\mathrm{M}$ & SD & $\mathrm{n}$ & Difference & & & \\
\hline Motivation & 125.62 & 6.68 & 165.20 & 6.95 & 35 & $-42.69,-36.45$ & .113 & -25.7 & .000 \\
\hline
\end{tabular}


As displayed in Table 4.There are statistically major differences between pretest and posttest on the mean scores of motivations for the experimental group. Results show that there is a highly significant effect on the motivation of students in the experimental group as ( $\mathrm{t}=-25.7$ and $\mathrm{p}<.001)$

Table 5: Descriptive Statistics and paired sample t-test for Academic Achievement on Control group $(N=35)$

\begin{tabular}{|c|c|c|c|c|c|c|c|c|c|}
\hline \multirow[b]{2}{*}{ Outcome } & \multicolumn{2}{|c|}{ Pre-test } & \multicolumn{2}{|c|}{ Post-test } & \multicolumn{2}{|c|}{ 95\% CI for Mean } & \multirow[b]{2}{*}{$\mathrm{r}$} & \multirow[b]{2}{*}{$\mathrm{t}$} & \multirow[b]{2}{*}{$\mathrm{P}$} \\
\hline & $\mathrm{M}$ & SD & $\mathrm{M}$ & SD & $\mathrm{N}$ & Difference & & & \\
\hline English & 44.14 & 10.5 & 44.37 & 10.3 & 35 & $-1.00,0.549$ & .977 & -.597 & .554 \\
\hline
\end{tabular}

Table 5. Shows the mean differences between academic achievements on the pre and posttests of the control group. On all subjects, there are statistically non-significant differences between pre-test and post-test on the mean scores of English, for the control group. Results show that there is no significant effect on the performance of students in the control group.

Table 6: Descriptive Statistics and paired sample t-test for Academic Achievement on Experimental group $(N=35)$

\begin{tabular}{|c|c|c|c|c|c|c|c|c|c|}
\hline \multirow[b]{2}{*}{ Outcome } & \multicolumn{2}{|c|}{ Pre-test } & \multicolumn{2}{|c|}{ Post-test } & \multicolumn{3}{|c|}{ 95\% CI for Mean } & \multirow[b]{2}{*}{$\mathrm{t}$} & \multirow[b]{2}{*}{$\mathrm{P}$} \\
\hline & $\mathrm{M}$ & SD & $\mathrm{M}$ & SD & $\mathrm{n}$ & Difference & $\mathrm{R}$ & & \\
\hline English & 42.20 & 7.88 & 53.86 & 7.10 & 35 & $-14.79,-8.52$ & .262 & -7.55 & .000 \\
\hline
\end{tabular}

Table 6 shows the mean differences between academic achievements on the pre and post-tests of the experimental group. On all subjects, there are statistically significant differences between pretest and post-test on the mean scores of English, for the experimental group. Results show that there is a highly significant effect on the performance of students in the experimental group.

Table 7: Means, Standard Deviation and t-value for Control and Experimental groups on PreIntrinsic motivation towards accomplishment, subscale of Academic Motivation Scale $(N=70)$

\begin{tabular}{|c|c|c|c|c|c|c|c|c|}
\hline \multirow[t]{2}{*}{ Variables } & \multicolumn{2}{|c|}{ Control $(\mathrm{n}=35)$} & \multicolumn{2}{|c|}{$\begin{array}{c}\text { Experimental } \\
(\mathrm{n}=35)\end{array}$} & \multirow{2}{*}{$\begin{array}{c}\mathrm{t} \\
(68)\end{array}$} & \multirow[b]{2}{*}{$\mathrm{P}$} & \multicolumn{2}{|c|}{$95 \%$ C. L } \\
\hline & $\mathrm{M}$ & SD & $\mathrm{M}$ & SD & & & LL & $\mathrm{UL}$ \\
\hline $\begin{array}{l}\text { Pre-Intrinsic motivation to } \\
\text { accomplish }\end{array}$ & 18.37 & 3.97 & 18.51 & 2.83 & -.173 & .863 & -1.790 & 1.504 \\
\hline
\end{tabular}

The table shows that there is an insignificant mean difference between control and experimental groups on the score of pre intrinsic motivation towards accomplishment, subscale of the Academic Motivation Scale (AMS). Figures show that the control group has a slightly higher mean as compared to the experimental group $(\mathrm{M}=18.37, \mathrm{SD}=3.97$ and $\mathrm{M}=18.51, \mathrm{SD}=2.83)$. The mean difference between control and experimental groups towards pre intrinsic motivation towards accomplishment, subscale of Academic Motivation Scale (AMS) is not statistically significant as pvalue $>.05$

\section{Findings}

1. It was found that the learners who were exposed to traditional instruction showed lower mean value as compared to those who were taught by implementing Differentiated Instruction (Table 5). There was a significant difference in the student's motivational level between the Experimental group vs. Control group (Table 3). If students' diversity is considered, then learners get more opportunities for better construction of knowledge as compared to traditional instructional methodology and they feel more confident to study. Students feel more engaged in class which helps them in higher academic scores.

2. The result of the study showed that diverse learners with differentiated instructional strategies performed well in the experimental group than their counterparts who were in traditional classes (Table 4). One such research was done by Mc Admin (2001) in which he had also applied the same strategy and showed improvement in scores of weak students in the Rockwood School.

3. Results showed significant improvement in the achievement score of learners exposed to Differentiated Instruction (Table 6). A study was carried out in 2007 by "Goddard and Goddard", whose findings match with this study, also indicated improvement in academic scores of learners and enhanced motivation.

4. The results also indicated that the students were more motivated and engaged in learning, their behavior was also improved. Different strategies readily appealed to their learning profiles and 
it proved very effective in the experimental group. Students took keen interest in their lessons and their spirit for learning remained throughout the lesson.

\section{Discussion and Conclusions}

After a thorough examination of the data, the conclusion was drawn that the differential approach enhances both the variables i.e. motivation \&performance. It is advantageous and helpful not only in enhancing the motivation but also the academic achievement of the learners.

To cope with the variance among learners and to address the growing diversity in classrooms, the implementation of a differential approach is most appropriate. By comparing differentiated instruction and traditional instruction, it is concluded that in differentiated instruction classrooms the learners have more chances to interact and converse with each other. This study examined the impact of differential instructional approach on motivation and performance of diverse learners at secondary schools. The researcher reported a few challenges. Much time is required for planning activities and setting a timetable for individuals and groups. It also seemed difficult to cope with the individual variance and differences as well as the learner's priority to keep himself alone than in the whole class or group. The researcher was successful in increasing diverse learners' motivation and academic achievement overall in the general classroom setting through differentiated instruction. It implies that teachers ought to prepare such instructional design which accommodates all learners' differences based on their choices and interest which in turn enhances their motivation. The teachers should continue to offer students choices based on learning style and, differentiated learning tasks to diverse students. By applying differentiated instruction most of the learners can be treated in a different way which makes learning approachable to every student. Differentiated instruction empowers teachers to target multiple learning styles through different themes, adapted content, delivery, and assessment and evaluation options. Since diverse learner's motivational level and academic achievement were raised as seen in the findings of the study, so the researcher concluded that differentiated instruction was an effective teaching strategy.

\section{Recommendations}

1. Differential Instruction being a teaching approach encompasses variance in the classrooms by providing opportunities for every student to learn and improve. Hence, at the secondary level teachers can benefit from this approach.

2. It is prescribed that utilization of the differentiated instruction must be implemented and adopted by the teachers in our institution at the secondary level.

3. There is the possibility that most of the teachers may not be aware of the differentiated approach, they must be acquainted with the use of this method through workshops and seminars.

4. The learners who were exposed to differentiated instruction were highly motivated and showing high score ability in academic achievement as compared to those learners who were instructed by traditional teaching. So, the teacher ought to be extra careful in the selection of content and mode of instruction to attain the desirable outcomes.

5. Variance in classrooms requires teachers to be well-versed with the subject matter and competent to deal with diverse learners.

\section{References}

Abbott, Oscar Eban (2006) Urban and non-urban elementary school Principals' perception of attributes of effective schools associated with meeting Adequate Yearly Progress (AYP). Dissertation Abstract International Vol. 67(12): 4391-A.

Akey M Theresa (2006) School Context, Student Attitudes and Behaviour, and Academic Achievement: An Exploratory Analysis. MDRC Building knowledge to Improve Social Policy.

Amandeep and Gurpreet (2005) A study of teacher effectiveness in relation to teaching competency. Recent Researches in Education and Psychology, Nos.I-II.

Amuche, C. Igomu, and Saleh. A. Dauda (2013) Principals managerial competence as a correlate of students' academic performance in ESWA secondary schools in North Central Nigeria. Journal of Education and Practice, Vol.4 (8).

Anderson, K. M. (2007). Tips for teaching: Differentiating instruction to include all students. Preventing School Failure, 51(3), 49-53. http://dx.doi.org/10.3200/PSFL.51.3.49-54 
Barkousis, V., Haralambos, T., Grouis, G., Sideridis, G. (2008). Achievement goals as a Measure for Motivation in University Students, Contemporary Educational Psychology, 19, 430-446

Beck, C. (2001). Matching teaching strategies to learning style preferences. The Teacher Educator, $37(1), 1-15$.

Beecher, M., \& Sweeny, S. (2008). Closing the achievement gap with curriculum enrichment and differentiation: One school 's story. Journal of Advanced Academics, 19(3), 502-530.

Belenky, D. M., \& Nokes, T. J. (2009). Examining the role of manipulatives and metacognition on engagement, learning, and transfer. The Journal of Problem Solving, 2(2), 102-129.

Berliner \& R. Calfee (Eds.), Handbook of Educational Psychology (pp. 491-549). New

Berliner \& R. Calfee (Eds.), Handbook of Educational Psychology (pp. 491-549). New

Berliner \& R. Calfee (Eds.), Handbook of Educational Psychology (pp. 491-549). New

Blaz, Deborah (2016). Differentiated Instruction: A Guide for World Language Teachers.

Burnett, B., \& Lampert, J. (2011). Teacher education and the targeting of disadvantage. Creative Education, 2(5), 446-451.

Campbell, B. (2008). Handbook of differentiated instruction using the multiple intelligences. Boston, MA: Pearson Education.

Giambo, D. A. (2010). High-stakes testing, high school graduation, and limited English proficient students: A case study. American Secondary Education, 38(2), 44-56.

Gibbone, A., Rukavina, P., \& Silverman, S. (2010). Technology integration in secondary physical education: Teachers' attitudes and practice. Journal of Educational Technology Development \&Exchange, 3(1), 27-42. Retrieved fromhttp://www.ebscohost.com

Kuehn, L. (2010). So long, constructivism. Hello smart! Our Schools/Our Selves, 19(2), 129-134.

Miller, M. A. (2011). Differentiated reading instruction and classroom management structures that promote reading development (Ph.D.). University of Florida.

Mitchell, D. (2017): 'Geography Teachers and Curriculum Making in Changing Times', International Research in Geographical and Environmental Education, 25, pp. 121-133.

Stager, A. (2007). Differentiated instruction in mathematics. M.A. dissertation, Caldwell College, United States-New Jersey. Retrieved April 5, 2016, from Proquest Digital Dissertations database.

Stainback, S., \& Stainback, W. (1996). Bringing research-based practice in reading intervention to scale. Learning Disabilities Research \& Practice, 18(3), 201-211.

Sunil BehariMohanty (2009): "School Improvement, Teacher Empowerment and Teacher Education: An International Scenario". Indian Journal of Teacher Education, Vol. 6 No. 1, June 2009, 53 69.

Tomlinson, C. A., (2009). Advanced differentiated instruction. Pre-conference workshop presented at the annual meeting of the Association for Supervision and Curriculum Development, Orlando, FL.

Trace, Hall, Nicole, Strangman, and Meyer, Anne. (2011). Differentiated Instruction and Implications for UDL Implementation. Downloaded on October $5^{\text {th }}, 2017$. The article is available at http://aim.cast.org/learn/historvarchive/backgroundpapers/differentiatedinstructionudl

Vallerand, R., Pelletier; L., Blais, M., Briere, N., Senecal, C., Vallieres, E. (1992). The Academic Motivation Scale: A measure of intrinsic, extrinsic, and motivation in education. Educational and Psychological Measurement, 52, 1003-1017. 